University of Nebraska - Lincoln

DigitalCommons@University of Nebraska - Lincoln

Faculty Publications from the Harold W. Manter Laboratory of Parasitology

10-1979

\title{
A New and Unusual Eimerian (Protozoa: Eimeriidae) from the Liver of the Gulf Killifish, Fundulus grandis
}

\author{
Donald W. Duszynski \\ University of New Mexico, eimeria@unm.edu \\ Mobashir A. Solangi \\ Gulf Coast Research Laboratory \\ Robin M. Overstreet \\ Gulf Coast Research Laboratory, robin.overstreet@usm.edu
}

Follow this and additional works at: https://digitalcommons.unl.edu/parasitologyfacpubs

Part of the Parasitology Commons

Duszynski, Donald W.; Solangi, Mobashir A.; and Overstreet, Robin M., "A New and Unusual Eimerian (Protozoa: Eimeriidae) from the Liver of the Gulf Killifish, Fundulus grandis" (1979). Faculty Publications from the Harold W. Manter Laboratory of Parasitology. 187.

https://digitalcommons.unl.edu/parasitologyfacpubs/187

This Article is brought to you for free and open access by the Parasitology, Harold W. Manter Laboratory of at DigitalCommons@University of Nebraska - Lincoln. It has been accepted for inclusion in Faculty Publications from the Harold W. Manter Laboratory of Parasitology by an authorized administrator of DigitalCommons@University of Nebraska - Lincoln. 


\section{A NEW AND UNUSUAL EIMERIAN (PROTOZOA: EIMERIIDAE) FROM THE LIVER OF THE GULF KILLIFISH, Fundulus grandis ${ }^{\text {}}$}

DONALD W. DUSZYNSKI, Department of Biology, The University of New Mexico, Albuquerque, New Mexico 87131, USA.

MOBASHIR A. SOLANGI and ROBIN M. OVERSTREET, Parasitology Section, Gulf Coast Research Laboratory, Ocean Springs, Mississippi 39564, USA.

Abstract: Oocysts and sporocysts of Eimeria funduli sp.n. are described from the Gulf killifish, Fundulus grandis, on the basis of light microscopy, transmission and scanning electron microscopy, and location in the liver of infected hosts. The spherical sporulated oocysts of $E$. funduli isolated from liver tissue measure 20-31 (25) $\mu \mathrm{m}$ across with ovoid sporocysts $9-11 \times 5-7(10 \times 6) \mu \mathrm{m}$. A micropyle, polar granule, and oocyst residuum are absent, but sporocysts have Stieda and substieda bodies, a few residual granules, and 10-25 (15) unique projecting structures with expanded distal portions that we term "sporopodia". Sporopodia 1.3 (2) $\mu \mathrm{m}$ high support a transparent membrane that completely surrounds the sporocyst. Sporozoites have one large posterior refractile body. Ultrastructurally, the oocyst wall consists of two thin layers of granular material: an electron-dense outer layer with a rough external surface and an electron-lucent inner one of approximately equal thickness. One or two unit membranes line the inner surface of the inner layer. Each layer is $40-60(55) \mathrm{nm}$ thick. The sporocyst wall, 78-130 (110) nm thick, consists of an electron-lucent material with the outer surface being more electron dense and giving rise to osmiophilic sporopodia; closely associated with these and the outer surface are one or two unit membranes. A thin osmiophilic layer of fine granular material lines the inner surface.

\section{INTRODUCTION}

An epizootic of a hepatic coccidian in the Gulf killifish, Fundulus grandis, occurred in Mississippi estuaries. A few individuals from specific localities harbored the organism in 1969, but prevalence remained low for numerous killifish examined until March, 1975 when about $10 \%$ of the fish examined had infections. Moreover, of about 300 fish examined from 1977 to early 1979 , all had infections regardless of the age of fish or the specific geographic locality from Pascagoula to Bay St. Louis, Mississippi.

The eimeriid has not been described, and that is the purpose of this paper. Only Fantham and Porter ${ }^{-}$in Canada and Overstreet ${ }^{*}$ in Louisiana have noted unidentified eimerians in killifish; those may or may not be the identical organism.

\section{MATERIALS AND METHODS}

Sporulated oocysts of Eimeria funduli were harvested by grinding the livers of naturally-infected $F$.grandis in a Waring blender for $10 \mathrm{sec}$ and filtering the material through 20-, 40-, and 60-mesh brass screens. Oocysts were stored in $2 \%$ $(w / v)$ aqueous $\mathrm{K}_{2} \mathrm{Cr}_{2} \mathrm{O}_{7}$ solution at $4-5 \mathrm{C}$ until they could be used. Prior to microscopic study, they were concentrated by sugar flotation (sp. gr. 1.15),

This study was conducted in cooperation with the U.S. Department of Commerce, NOAA, National Marine Fisheries Service, under PL 88-309, Project 2-325-R. It was also supported, in part, by a University of New Mexico Research Allocations Grant-in-Aid. 
washed, and reconcentrated three times in tap water by centrifugation.

For light microscopy, washed oocysts were measured with an ocular micrometer and photomicrographs were made on Panatomic-X $35-\mathrm{mm}$ film in a Zeiss Universal Photomicroscope equipped with a $100 \times$ Neofluar objective. All measurements are in micrometers unless otherwise stated with means in parentheses following ranges.

For electron microscope studies, washed oocysts were suspended in $15 \%$ gluteraldehyde in $0.2 \mathrm{M}$ cacodylate buffer, ground slightly in a teflon tissue grinder, and allowed to fix overnight. To examine them with the TEM, a fixed suspension was rinsed in buffer, postfixed in $1 \% \mathrm{OsO}_{4}$ in $0.1 \mathrm{M}$ cacodylate buffer for $1 \mathrm{hr}$, rinsed several times in buffer, dehydrated through a graded series of ethanol and two changes of propylene oxide, and embedded in Spurr's medium. ${ }^{9}$ Ultrathin sections were stained in uranyl acetate and lead citrate and then examined with an AEI Corinth 275 TEM. Procedures for the SEM included rinsing the fixed oocyst suspension in buffer and placing several drops of the suspension on $12 \mathrm{~mm}$ diameter coverslips previously treated with poly-l-lysine. ${ }^{6} \mathrm{We}$ allowed $30 \mathrm{~min}$ for the oocysts to attach; material on the coverslips was then rinsed in buffer, postfixed in $1 \% \mathrm{OsO}_{4}$ for $1 \mathrm{hr}$, and dehydrated in a graded series of ethanol. The preparations were dried by the criticalpoint method using liquid $\mathrm{CO}_{2}$, sputtercoated with gold-palladium, and examined with an ETEC Autoscan SEM.

For histological studies, liver tissue was fixed in Bouins', embedded in Paraplast-Plus ${ }^{(\mathrm{c})}$, sectioned at $5 \mu \mathrm{m}$, and stained with $\mathrm{H} \& \mathrm{E} .^{5}$

\section{RESULTS}

The following description is based on 100 sporulated oocysts pooled from the livers of 14 naturally infected $F$. grandis. The oocysts were measured within 73 days after being separated from infected livers, but their exact age is unknown since the fish were naturally infected.

Eimeria funduli sp. n. (Figs. 1-26)

Type Host. Fundulus grandis Baird and Girard, Gulf killifish (Cyprinodontidae).

Type Locality. Ocean Springs, Mississippi. Other Localities. Throughout estuaries of Mississippi and Louisiana.

Site In Host. Sporulated oocysts in hepatocytes; in infected livers oocysts seen individually and in both small and large groups enclosed in connective tissue capsules (Figs. 9, 10, 12-15).

Etymology. The specific name refers to the type host.

Light Microscopic Observations (Figs. 1-11). Oocyst wall of uniform thickness 1 wide, consisting of 2 colorless layers of $\sim$ equal thickness, with outer layer transparent and inner layer opaque; micropyle, polar granules, and oocyst residuum lacking; sporulated oocysts spherical (Figs. 1-4, 11), 20-31 (24.5) across; sporocysts ovoid (Figs. 5-8), 9-11 $\times 5-7(10 \times 6)$, with $\mathrm{L}: \mathrm{W}$ ratio $1.45-2.02$ (1.68); Stieda body present at apex of sporocyst (Figs. 1, 5, 6, 11); substieda body small (Fig. 1), usually obscured by sporozoites (Figs. 2-11); unique foot-like structures, that we term "sporopodia", associated with sporocyst's outer surface; sporopodia project irregularly over entire outer wall (Figs. 2, 3, 4, 7, 11), numbering 10-25 (14.5) per sporocyst, apparently supporting transparent matrix; matrix 1-3 (1.7) wide, completely surrounding sporocyst on all sides (Figs. $2-4,7,11$ ); sporocyst residuum small, usually consisting of $1-4$ refractile granules located between sporozoites (Figs. 2, 5, 6); sporozoites with 1 refractile body near posterior end (Figs. 1, 8, 11).

TEM Observations (Figs. 20-26). Oocyst wall consisting of 2 thin layers of granular material with different densities; outer layer osmiophilic and same width but less electron-lucent than inner layer (Figs. 20-21), measuring 40-60 (55) 


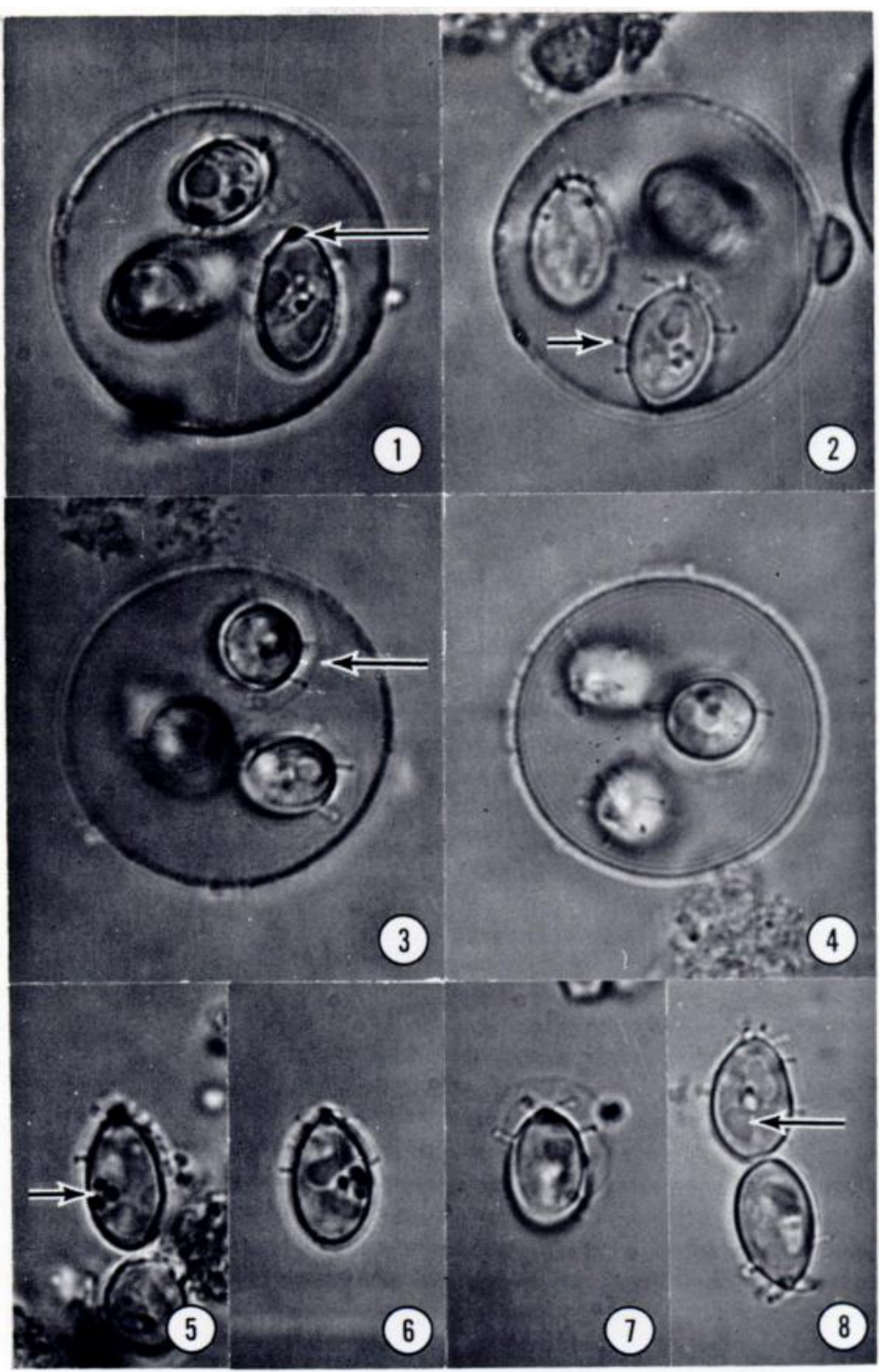

FIGURES 1-8. Sporulated oocysts (1-4) and sporocysts (5-8) of Eimeria funduli from the liver of Fundulus grandis. $\times 1860$. FIG. 1. Note substeida body (arrow). FIG. 2. Note sporopodia projecting from sporocyst wall (arrow). FIG. 3. Note transparent membrane surrounding sporocyst and apparently supported by sporopodia. FIG. 4. Sporopodia projecting irregularly from surface of sporocyst. FIG. 5. Note sporocyst residual granules (arrow). FIGS. 6, 7. Note the transparent membrane is only occasionally visible on sporocysts removed from oocysts. FIG. 8. Note single refractile body in sporozoite (arrow). 

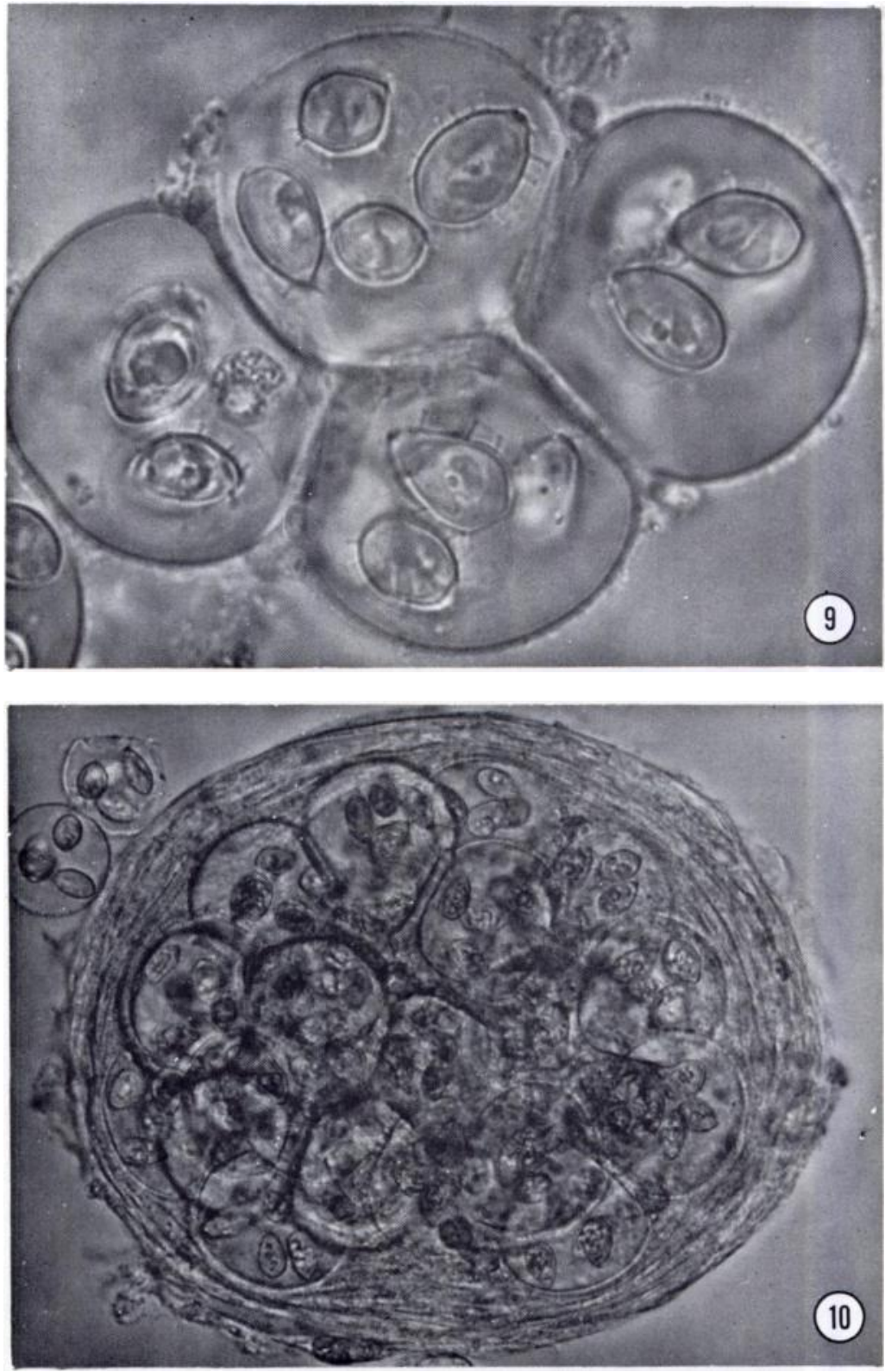

FIGURES 9, 10. Sporulated oocysts of Eimeria funduli separated from liver tissue of Fundulus grandis. FIG. 9. Four oocysts stuck together giving appearance of adhesion of oocyst walls $(\times 1860)$. FIG. 10. Aggregate of oocysts surrounded by host connective tissue $(\times 640)$. 


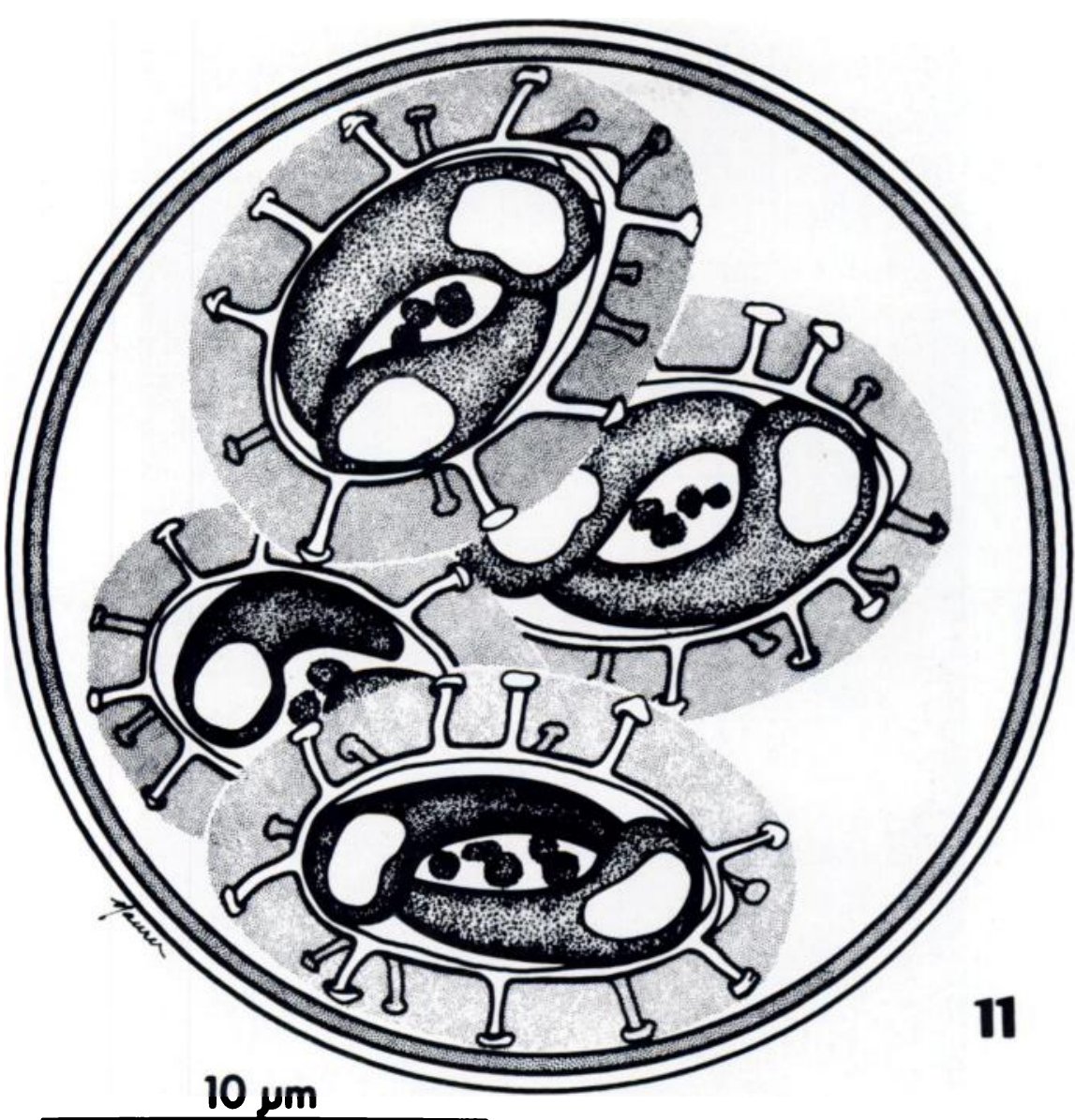

FIGURE 11. Diagrammatic representation of a sporulated oocyst of Eimeria funduli.

$\mathrm{nm}$ thick, consisting of various sized granules and presenting rough outermost surface, with occasional relatively large electron-lucent spherical bodies (Fig. 21); inner layer consisting of smaller more homogeneous granules, with innermost surface lined by 1 or 2 unit membranes; sporocyst wall (Figs. 22,23 ) consisting of rather homogeneous electron-lucent material, 78-130 (110) $\mathrm{nm}$ thick, with outermost surface more osmiophilic than inner portion and giving rise to more electron-dense sporopodia (Figs. 24-26); outer surface and sporopodia associated with 1 or 2 membranes; innermost sporocyst surface lined by thin layer of osmiophilic granular material.

SEM Observations (Figs. 16-19). Oocyst wall bi-layered with the outermost layer rough and inner one smooth (Fig. 18); layers corresponding well with TEM (Figs. 20, 21), but subtle roughness of outer surface not apparent at light level (Figs. 1-4); sporocyst wall smooth, with outer surface elaborated into mushroom-shaped sporopodia (Figs. 16, 19); sporopodia closely associated with 1 


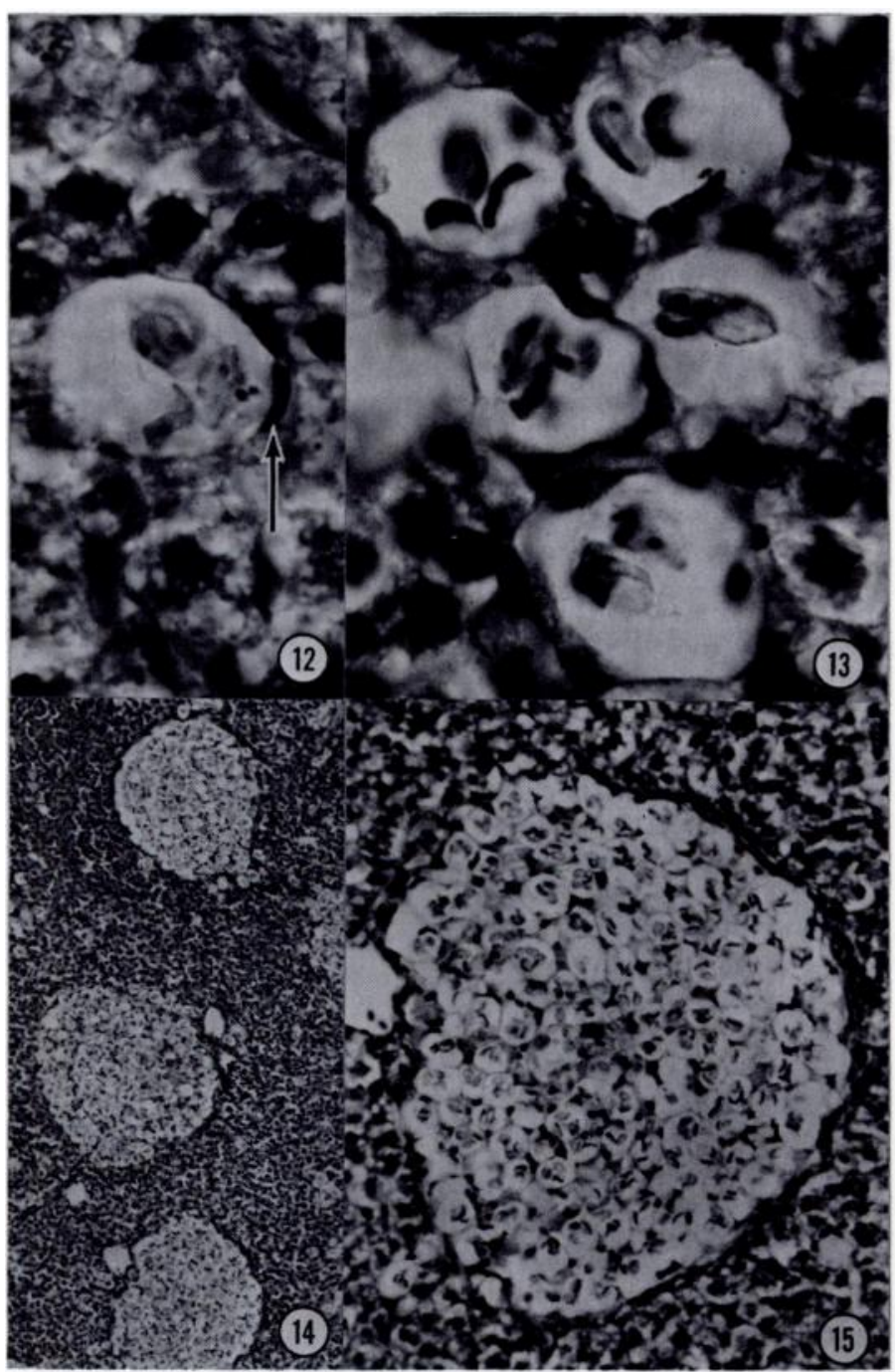

FIGURES 12-15. Tissue sections of liver from Fundulus grandis infected with Eimeria funduli (H\&E). FIG. 12. A single oocyst apparently developing within a hepatocyte. Note compressed host cell nucleus, arrow $(\times 1460)$. FIG. 13. Five oocysts developing in close proximity to each other; when liver tissue is ground or passed through brass screens, oocysts are usually released in tightly compressed groups (see FIG. 9) $(\times 1460)$. FIG. 14. Low power section $(\times 90)$ showing packets of hundreds of sporulated oocysts which have been walled off by host tissue reaction. These packets can be released from ground-up tissue as entire units (see FIG. 10). FIG. 15. Enlargement $(\times 260)$ of lower packet from FIG. 14 showing hundreds of sporulated oocysts. 

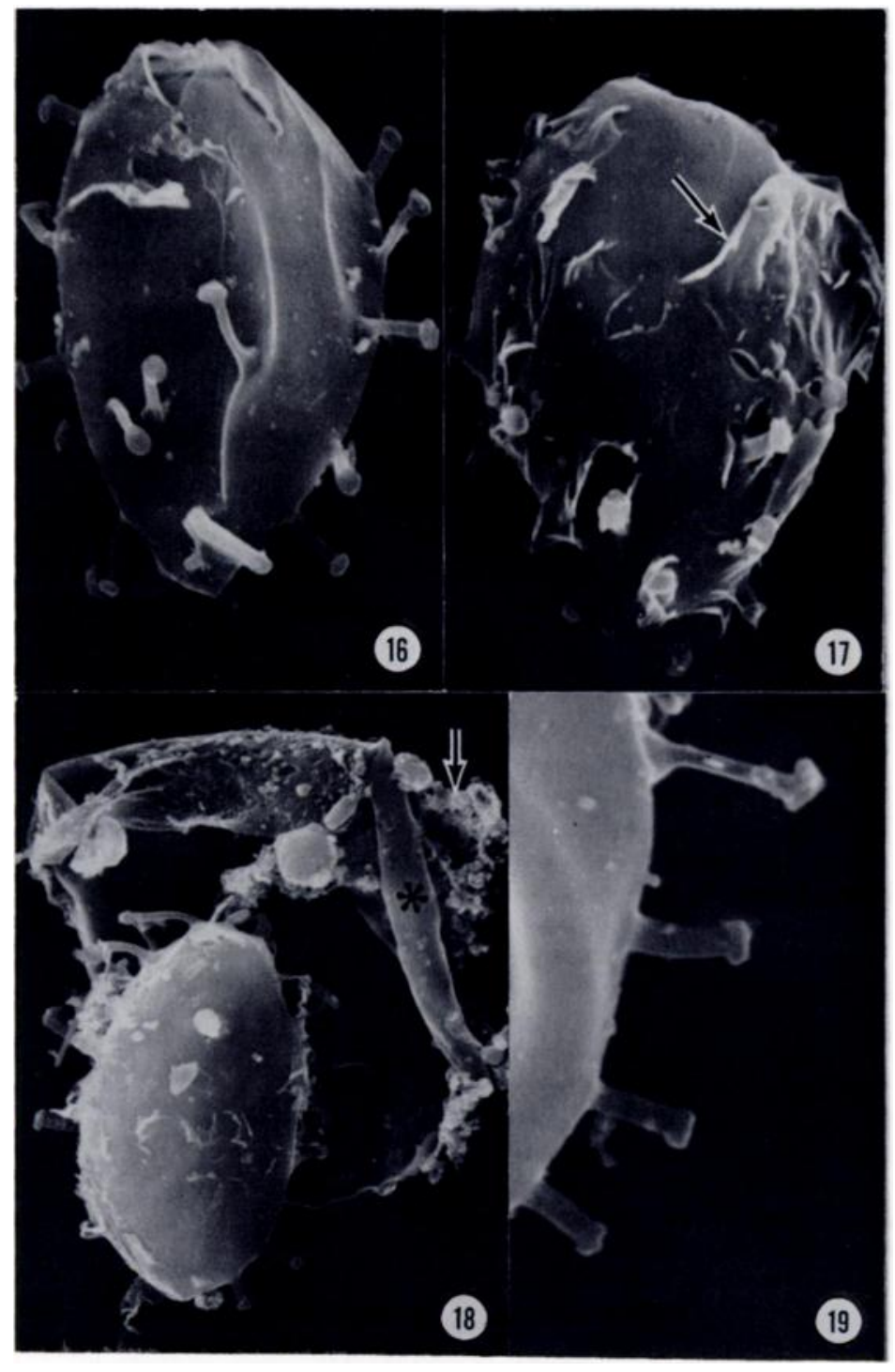

FIGURES 16-19. Scanning electron-micrographs of intact sporocysts and broken oocyst wall (FIG. 18) of Eimeria funduli. FIG. 16. Sporocyst showing apparent random arrangement of sporopodia $(\times 10,000)$. FIG. 17. Sporocyst with remnant of membrane (arrow) associated with sporopodia and apparently surrounding all intact sporocysts (see FIGS. 2-4, 7) $(\times 10,000)$. FIG. 18. Sporocyst adjacent to its broken oocyst; oocyst wall is bi-layered with rough outer layer (arrow) beginning to separate from smooth inner one $\left(^{*}\right)(\times 8,000)$. FIG. 19. Close-up of sporopodia showing resemblance to long-stalked mushrooms $(\times 20,000)$. 
or 2 membranes (Fig. 17); these membranes apparently supported by sporopodia in living sporocysts (Figs. 2 4).

Prepatent And Patent Periods. Unknown, but no oocysts seen in fecal debris of six naturally infected adult fish $\sim 2$ years old. We took nine biweekly or weekly samples of water from a 10-gal aquarium between 6 and $15 \mathrm{wks}$ after fish had been placed into tank, and these showed no oocysts by sugar flotation. At first, samples were taken from the bottom, middle, and top of tank until a second experiment showed that cleaned oocysts harvested from liver tissue did not float in $10-15 \%$ seawater.

\section{DISCUSSION}

When describing coccidians on the basis of the exogenous stage, as much detail as possible should be presented for future comparisons with new and with redescribed species. Consequently, we provide photomicrographs of living oocysts along with a line drawing because the latter represents an artist's schematic interpretation and does not necessarily illustrate individual variability seen in living specimens. In addition, the day during patency when oocysts are discharged and their age due to storage can be important factors contributing to structural dimensions and presence of residua in oocysts and sporocysts. 2,3 For these reasons we measured sporulated oocysts from several hosts, but could not determine exactly the age of those oocysts because the hosts were naturally infected.

The oocyst wall of eimerians from marine fishes has been examined by TEM only twice. ${ }^{1,7}$ In both $E$. variabilis from the pyloric cecum and rectum of a sculpin (Cottus bubalis) ${ }^{\prime}$ and $E$. gadi from the swim bladder of haddock (Melanogrammus aeglefinus) ${ }^{7}$ the oocyst wall was reported to consist of a single membrane. Neither study, however, described nor pictured the wall in detail. The oocyst wall of $E$. funduli is much thicker than the walls of both E. gadi and $E$. variabilis and consists of two distinct layers. Nonetheless, it is still very thin when compared to those of most eimerians. However, the thinness of a biological structure is not directly correlated with its permeability. In our work an inability to achieve good fixation of sporocysts in intact oocysts indicated the oocyst wall was impermeable to the chemicals we used; we resolved this by breaking the oocyst walls during fixation (see Methods).

The sporocyst walls of piscine eimerians are usually thicker than their respective oocyst walls, but in $E$. funduli they are approximately equal in thickness. The sporopodia protruding from the sporocyst's outer surface help distinguish this form from all other eimerians. These structures somewhat resemble the tube feet of starfish, but they are not hollow or fluid-filled and were never seen to move in fresh oocysts or liberated sporocysts. At present we have no clue as to their possible function.

The development of $E$. funduli in the liver of its host, and apparently in hepatocytes rather than biliary epithelium, is another feature which distinguishes this species from all others. Also, there seems to be a sequence of events occurring in which oocysts (Fig. $12)$, as they increase in numbers in the liver, become congregated together (Fig. 13) until at some point the host is able to wall off large regions containing hundreds of sporulated oocysts (Figs. 10, 14, 15). Finally, we have some data that oocysts do not pass from the liver to the external environment with any frequency. Thus, infected fish must die or be eaten to release the parasite and that might suggest the presence of a transport or even intermediate host in this parasite's life cycle.

This description deals exclusively with parasites from $F$. grandis in the northern Gulf of Mexico. An additional paper will 


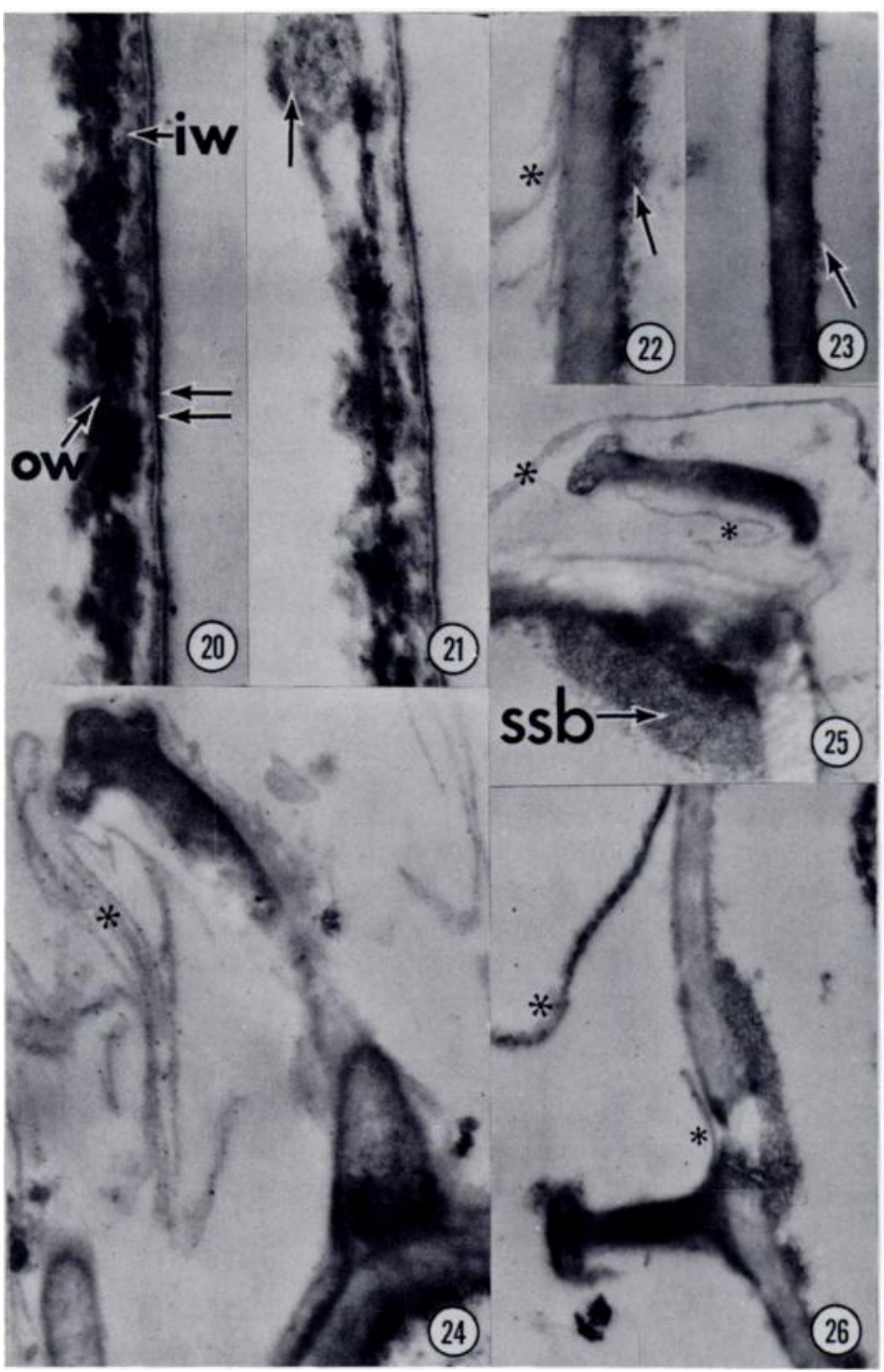

FIGURES 20-26. Transmission electron-micrographs of oocyst and sporocyst walls and sporopodia of Eimeria funduli. FIGS. 20,21. Oocyst walls with 2 layers. Note electron dense outer layer (ow), opaque inner layer (iw) and closely applied unit membranes (double arrows) that line inner layer. In some sections electron-lucent spherical bodies are seen in outer layer (arrow) $(\times 100,000)$. FIGS. 22, 23. Sporocyst walls appear different in thickness depending on angle of section and often have remnants of membrane material on outer surface $\left(^{*}\right)$ and a thin layer of fine granular material associated with inner surface of wall (arrow) $(\times 67,000)$. FIGS. 24-26. Sections through sporopodia. Note various membranes $\left({ }^{*}\right)$ associated with this structure and substieda body $(88 b)(\times 67,100,47,200$, and 48,100 , respectively). 
report other killifish hosts, other geographic regions where infections oc cur, life cycle of the organism, pathological alterations in the host, and a chemical means of controlling the disease. Eimeria funduli is the first species described from killifish and the thirty-fifth from a saltwater fish.

\section{Acknowledgements}

We thank Roswitha Buxton, Ronnie Palmer, Steve Shepard, and Dean Mattison for their technical assistance and Greg Minion for his patience and skill in preparing and photographing specimens with the TEM and SEM.

\section{LITERATURE CITED}

1. DAVIES, A.J. 1978. Coccidian parasites of intertidal fishes from Wales: Systematics, development, and cytochemistry. J. Protozool. 25: 15-21.

2. DUSZYNSKI, D.W. 1971. Increase in size of Eimeria separata oocysts during patency. J. Parasit. 57: 948-952.

3. - W.M. SAMUEL and D. GRAY. 1971. Three new Eimeria spp. (Protozoa: Apicomplexa) from muskoxen, Ovibos moschatus with redescriptions of $E$ faurei, $E$. granulosa, and $E$. ovina from muskoxen and from a Rocky Mountain bighorn sheep, Ovis canadensis. Can. J. Zool. 55: 990-999.

4. FANTHAM, H.B. and A. PORTER. 1948. The parasitic fauna of vertebrates in certain Canadian fresh waters, with some remarks on their ecology, structure and importance. Proc. Zool. Soc. London 117: 609-649.

5. HUMASON, G.L. 1972. Animal Tissue Techniques (3rd ed.). W.H. Freeman and Co., San Francisco, 641 pp.

6. MARCHIONDO, A.A., D.W. DUSZYNSKI and C.A. SPEER. 1978. Fine structure of the oocyst wall of Eimeria nieschulzi. J. Protozool. 25: 434-437.

7. ODENSE, P.H. and V.H. LOGAN. 1976. Prevalence and morphology of Eimeria gadi (Fiebiger, 1913) in the haddock. J. Protozool. 23: 564-571.

8. OVERSTREET, R.M. 1978. Marine maladies? Worms, germs, and other symbionts from the northern Gulf of Mexico. Mississippi-Alabama Sea Grant Consortium, MASGP-78-021, Ocean Springs, 140 pp.

9. SPURR, A.R. 1969. A low viscosity epoxy resin embedding medium for electron microscopy. J. Ultrastruct. Res. 26: 31-43. 